\title{
Does googling for preconception care result in information consistent with international guidelines: a comparison of information found by Italian women of childbearing age and health professionals
}

Eleonora Agricola ${ }^{1 *}$, Francesco Gesualdo ${ }^{1}$, Elisabetta Pandolfi ${ }^{1}$, Michaela V Gonfiantini ${ }^{1}$, Emanuela Carloni ${ }^{1}$, Pierpaolo Mastroiacovo ${ }^{2}$ and Alberto E Tozzi ${ }^{1}$

\begin{abstract}
Background: Preconception counseling is effective in reducing the risk of adverse pregnancy outcomes. The Internet is commonly used by women and health professionals to search for health information. We compared the consistency of preconception information found on the Internet with the recommendations published by American Journal of Obstetrics and Gynecology (AJOG) simulating a web search by women of childbearing age and health professionals.

Methods: We reviewed websites resulting from a Google search performed using search strings selected by Italian women of childbearing age and health professionals. We investigated if retrieved information was consistent with AJOG recommendations for preconception care. Logistic regression was used to compare presence of consistent recommendations between women and health professionals.

Results: The highest frequency of correct recommendations was found for folic acid supplementation (39.4\% of websites). Consistency of preconception information did not significantly differ between search strategies except for folic acid supplementation. "Communities and blogs" website category provided less frequently correct recommendations compared with "Medical/Public Agency" category (i.e. folic acid supplementation (aOR 0.254; Cl $0.098-0.664 ; p=<0.01)$. Commercial links, found in 60\% of websites, were associated with presence of correct recommendations excepting few items (i.e. physical exercise (aOR 1.127; Cl 0.331-3.840; $p=0.848$ ).
\end{abstract}

Conclusions: Preconception information found is poor and inaccurate regardless of the search is performed by women or health professionals. It is unlikely that information found on the web have any positive impact among women and health professionals in our setting. Strategies to improve preconception information on the web and education of health professionals for web searching of health information should be considered.

Keywords: Preconception, Adverse pregnancy outcomes, Folic acid, Google, Internet, Health information

\footnotetext{
* Correspondence: eleonora.agricola@gmail.com

'Bambino Gesù Children's Hospital IRCCS, Epidemiology, Unit Piazza S.

Onofrio 4, 00165, Rome, Italy

Full list of author information is available at the end of the article
} 


\section{Background}

Maternal health, appropriate lifestyle such as smoking and drinking cessation, folic acid supplementation and adoption of an appropriate diet before and at the time of conception are positively associated with fetal health and pregnancy outcomes [1-8]. Many conditions can be prevented through appropriate preconception counseling including i.e. infertility, miscarriage, gestational diabetes, pre-eclampsia, placenta abruption, birth defects and malformations, fetal restriction growth, low birth weight and prematurity.

International Health Agencies have therefore issued recommendations on preconception care indicating that prevention before conception is a crucial tool for identifying, modifying and reducing the risk factors for adverse pregnancy outcomes in women of childbearing age $[1,6,9,10]$.

Although recommended, preconceptional counseling is still infrequently practiced by women of childbearing age and rarely offered by healthcare professionals. On the other hand a large proportion of women search for information regarding fertility and pregnancy on the web [11]. Moreover, pregnant women use the Internet in order to gather information, make decisions, and get support on pregnancy by participating in social networks [12-14]. Along with patients, also physicians consult the Web to search for health information. They frequently use generic search engines, like Google, to improve their knowledge, quickly respond to patients' questions and make rapid diagnoses [15-19]. Recent surveys show that information found on the Internet influence physicians' behavior and their relationship with patients [20-22].

Quality of information found on the web may largely vary and Internet users may be misled by false or incomplete information regarding health [23].

Official surveys report that in $201060.1 \%$ of the population over the age of 15 use the Internet in the USA [24], while in $201156 \%$ of European population used it daily [25].

According to a report issued in 2010 by the Italian Institute of Statistics (ISTAT), in Italy Internet use is $48.9 \%$ in the population over the age of 6 . Up to $87 \%$ of women of childbearing age navigate the Internet, and $46.5 \%$ of them use the web to search for health information [26]. An European survey on generic medical practices conducted in 2007 showed that $70.7 \%$ of Italian general practitioners use the Internet and $81.4 \%$ have a computer in their consultation room [27]. Moreover, a study performed in 2011 on Italian pediatricians showed that $71.9 \%$ of them went online during their practice [20].

It is likely that patients and health professionals use different approaches in searching information on preconception care through the Internet and it is not known if different search strategies result in different level of consistency with current recommendations.

We therefore conducted a study to compare the frequency of web information on preconception care consistent with current guidelines as if a web search on this topic was performed by women of childbearing age who plan a pregnancy or by health professionals.

\section{Methods}

In this study we reviewed a group of websites found through a number of simulated web searches on Google by Italian users.

\section{Search strings selection}

By means of separate interviews, we investigated the likely search strings for a web search on preconception care in two groups of individuals: 21 women planning a pregnancy and 18 health care professionals, including gynecologists, pediatricians, neonatologists and geneticists. Mean age of the interviewed women was 32.02 years, $80 \%$ of them reported to be employed while $65 \%$ had a University degree. The interviews were conducted by email. Interviewees were invited to provide at least two search strings that they have used to perform a web search on preconception topics. Respectively, the two groups generated a list of 35 and 38 search strings excluding double entries.

We then submitted each of the strings into Google Adwords (Keyword Tool), which is a tool that reports the actual web search volume for a specific country in a specific period of time (Table 1) [28]. Based on the obtained search volume ranks, we selected the 12 strings with the highest volume score for each group (women and health professionals: 24 total search strings).

\section{Search and selection of websites}

We launched 24 searches on Google using each of the selected search strings in a single session on October 4th, 2011. For each search, the first search engine result page (SERP) for each search string was saved on a hard disk for off line review (list available on request). Each SERP showed a total of 10 websites. On the same day, the web pages were saved on a hard disk using an offline browser and limiting the sublink download to a depth of three levels. The sponsored websites appearing on the SERP were not included in the analysis.

\section{Review process}

In order to analyze the information quality on preconception care, we created a checklist of 19 items summarizing recommendations published by the American Journal of Obstetrics and Gynecology (AJOG) $[2,9]$.

The review process for each item was conducted to find out whether it corresponded to: a) absent, incorrect or incomplete recommendation; or b) correct and 
Table 1 List of search strings chosen by women of childbearing age and health professionals and the corresponding Google Adwords (Keywords Tool) search volumes

\begin{tabular}{|c|c|}
\hline Search strings of women of childbearing age & Google Adwords Keyword Tool search volumes \\
\hline Pregnancy & 3350000 \\
\hline Mums & 550000 \\
\hline Menstruation & 550000 \\
\hline Ovulation & 301000 \\
\hline Maternity & 246000 \\
\hline To get pregnant & 165000 \\
\hline Conception & 135000 \\
\hline Fertile period & 90500 \\
\hline Amniocentesis & 49500 \\
\hline To have a baby & 22200 \\
\hline Genetic diseases & 8100 \\
\hline Check up before pregnancy & 720 \\
\hline Search strings of health professionals & Google Adwords Keyword Tool search volumes \\
\hline Toxoplasmosis & 49500 \\
\hline Genetic diseases & 8100 \\
\hline Preconception & 1900 \\
\hline Folic acid before conception & 1000 \\
\hline Check up before conception & 480 \\
\hline Reproductive health & 110 \\
\hline Pre-conception drugs & 46 \\
\hline Pre-conception lifestyle & $-*$ \\
\hline Pre-conception obesity & $-^{*}$ \\
\hline Pre-conception prevention & $-^{*}$ \\
\hline Pre-conception chickenpox & $-^{*}$ \\
\hline Pre-conception rubella & $-*$ \\
\hline
\end{tabular}

complete recommendation. The web pages resulting from the searches were reviewed by a single operator (EA) based on the checklist.

We recorded the type of website choosing among five categories, as follows: a) Medical/Public Agencies: web pages with a clear affiliation to a hospital, a University, a medical centre, or a national health agency; b) Communities and blogs: websites managed and maintained by independent groups, where an interactive discussion with external users is displayed (social networks were not included in this category) c) Magazines: news magazine websites; d) Wikipedia: web pages belonging to the web encyclopedia; and e) Others: web pages not classifiable in the previous categories, including YouTube and sites belonging to any brand or industry.

\section{Statistical analysis}

We estimated that 182 websites (91 per group) were needed for finding significant differences in consistent recommendations with guidelines between the simulated search performed by women and the one performed by health care professionals, with the following assumptions: $80 \%$ power, $5 \%$ significance level and an expected frequency of correct recommendations of $20 \%$ in searches performed by women and of $40 \%$ in searches performed by health care professionals. We took into account a potential number of double entries of $30 \%$, due to website overlapping across searches conducted with different keywords, yielding a total sample size of 236 .

We described the frequency of recommendations by group (women or health professionals) and we used the 
chi square test for comparing proportions. We performed logistic regression models to assess the effect of search strategy on presence of a recommendation consistent with AJOG guidelines [2], adjusted for website category and presence of commercial links. We considered results significant when p-values were below or equal to 0.05 for both the univariate and multivariate analyses.

We used STATA 11 statistical software for analysis.

\section{Results}

From a total of 240 web pages (2 groups, 12 search strings per group, 10 web pages for each first SERP), 14 websites $(5.8 \%)$ were excluded because they were double entries within each search group. The remaining 226 were included in the analysis. Only 15 websites (6.6\%) overlapped between the search by women and the one by health professionals.

Table 2 shows the distribution of web categories by search group. The "Communities and blogs" category was the most represented overall; no social network website resulted from the simulated search. The second most frequent category was "Medical/Public Agency" while "Magazines" and "Wikipedia" were less frequent. Websites in the "Medical/Public Agency" category were three times more frequent in the health professional searches than in the women searches, while the "Communities and blogs" category was more frequently represented in the women searches.

Regarding the frequency of correct preconception recommendations, we found that they were infrequently reported regardless of the search strategy (Table 3). The most frequent recommendations consistent with AJOG guidelines were those regarding folic acid supplementation, rubella immunization, smoking cessation, doctor's appointment for preconception counseling, and doctor's advice for drug assumption. The least represented information were those about asthma control, avoiding contact with toxics and pesticides, and pertussis immunization. According to the multivariate analysis, correct recommendation on folic acid supplementation was found more frequently in searches performed by health professionals compared with women (Table 3). Moreover, most of the correct recommendations were significantly less represented in websites belonging to the Communities and blog category compared with those belonging to the Medical/Public Agency category: folic acid supplementation (aOR 0.254; CI 0.098-0.664; $\mathrm{p}=<0.01$ ), medical conditions control (aOR 0.141; CI 0.040-0.493; $\mathrm{p}<0.01$ ), vaccination status review (aOR 0.115; CI 0.024- 0.564; $\mathrm{p}<0.01$ ), doctor's appointment for preconception counseling (aOR 0.141; CI 0.037-0.546; $\mathrm{p}<0.01$ ).

We found that $60.0 \%$ of the websites presented commercial links; in particular, women's search strategy selected $68.3 \%$ websites containing a commercial link, compared with $51.7 \%$ obtained through health professionals' search strings $(p=0.008)$. Three websites were explicitly branded by pharmaceutical industries.

According to the multivariate analysis, only the least represented items were not positively associated with the presence of a commercial links [asthma control (aOR 2.734; CI 0.854-8.756; $\mathrm{p}=0.09)$, pertussis immunization (aOR 0.989; CI 0.131-7.467; $\mathrm{p}=0.992$ ), illicit drug cessation (aOR 2.350; CI 0.787-7.020; $\mathrm{p}=0.126$ ), physical exercise (aOR 1.127; CI 0.331-3.840; $\mathrm{p}=0.848$ ), avoiding toxics and pesticides (aOR 1.212; CI 0.235-6.261; $\mathrm{p}=0.818)]$.

\section{Discussion}

The likelihood of finding preconception care recommendations consistent with AJOG on the Internet was low, using search strings selected either by health professionals or by women of childbearing age.

This study shows that current approaches for searching preconception information on the web do not result in finding a complete and accurate set of recommendations, although we found no websites reporting totally incorrect preconception information. The obtained result is helpful to estimate the level of consistency of information found on the web considering the increasing use of the Internet for seeking health information by women and health care professional, and the importance of the web as a helpful

Table 2 Distribution of websites by category and search groups

\begin{tabular}{|c|c|c|c|c|}
\hline \multirow[b]{3}{*}{ Website category } & \multicolumn{2}{|c|}{ Search group } & \multirow[b]{3}{*}{$p$ value } & \multirow{3}{*}{$\begin{array}{l}\text { Total } \\
\text { N (\%) }\end{array}$} \\
\hline & Health care professionals & Women planning a pregnancy & & \\
\hline & $\mathrm{N}(\%)$ & $\mathrm{N}(\%)$ & & \\
\hline Public health agency, university, research entity & $40(36.4)$ & $12(10.3)$ & $<0.01$ & $52(23.0)$ \\
\hline Communities and blogs & $47(42.7)$ & $72(62.1)$ & $<0.01$ & $119(52.7)$ \\
\hline Magazines & $6(5.5)$ & $7(6.0)$ & NS & $13(5.8)$ \\
\hline Wikipedia & $3(2.7)$ & $9(7.8)$ & NS & $12(5.3)$ \\
\hline Others & $14(12.7)$ & $16(13.8)$ & NS & $30(13.3)$ \\
\hline Total & $110(100)$ & $116(100)$ & & $226(100)$ \\
\hline
\end{tabular}


Table 3 Distribution of correct recommendations by search group, univariate and multivariate analysis

\begin{tabular}{|c|c|c|c|c|c|c|c|c|c|}
\hline \multirow[b]{2}{*}{ Recommendation } & \multicolumn{3}{|c|}{ Search group } & \multicolumn{3}{|c|}{$\begin{array}{l}\text { Univariate } \\
\text { analysis }\end{array}$} & \multicolumn{3}{|c|}{$\begin{array}{c}\text { Multivariate } \\
\text { analysis }\end{array}$} \\
\hline & $\begin{array}{c}\text { Health care } \\
\text { professionals } \\
\mathrm{N}(\%)\end{array}$ & $\begin{array}{c}\text { Women planning } \\
\text { a pregnancy } \\
\mathrm{N}(\%)\end{array}$ & Total (\%) & OR & $95 \% \mathrm{Cl}$ & $\mathrm{p}$ & $\mathrm{aOR}$ & $95 \% \mathrm{Cl}$ & $p$ \\
\hline Take folic acid & $55(50.0)$ & $34(29.3)$ & 89 (39.4) & 2.41 & $1.35-4.33$ & 0.001 & 2.064 & $1.129-3.771$ & 0.018 \\
\hline Control medical conditions & $29(26.4)$ & $31(26.7)$ & $60(26.5)$ & 0.98 & $0.52-1.85$ & 0.951 & 0.929 & $0.470-1.836$ & 0.832 \\
\hline Control asthma & $17(15.7)$ & $7(6.1)$ & $24(10.8)$ & 2.88 & $1.07-8.06$ & 0.020 & 2.329 & $0.867-6.255$ & 0.094 \\
\hline Control diabetes & $30(27.3)$ & $27(23.3)$ & $57(25.2)$ & 1.24 & $0.65-2.36$ & 0.489 & 1.065 & $0.546-2.075$ & 0.854 \\
\hline Control epilepsy & $22(20.2)$ & $10(8.6)$ & $32(14.2)$ & 2.68 & $1.13-6.45$ & 0.013 & 2.117 & $0.874-5.129$ & 0.097 \\
\hline Go on diet if overweight or obese & $34(31.2)$ & $24(20.7)$ & $58(25.8)$ & 1.74 & $0.91-3.33$ & 0.072 & 1.823 & $0.924-3.599$ & 0.083 \\
\hline Review vaccination status & $20(18.2)$ & $27(23.3)$ & $47(20.8)$ & 0.73 & $0.36-1.47$ & 0.346 & 0.739 & $0.342-1.595$ & 0.441 \\
\hline $\begin{array}{l}\text { Verify immunity against rubella and } \\
\text { receive immunization if susceptible }\end{array}$ & $45(40.9)$ & $38(32.8)$ & $83(36.7)$ & 1.42 & $0.80-2.54$ & 0.204 & 1.347 & $0.702-2.584$ & 0.370 \\
\hline $\begin{array}{l}\text { Verify immunity against chicken pox } \\
\text { and } \\
\text { receive immunization if susceptible }\end{array}$ & $26(23.6)$ & $25(21.6)$ & $51(22.6)$ & 1.13 & $0.58-2.20$ & 0.708 & 0.793 & $0.386-1.629$ & 0.528 \\
\hline $\begin{array}{l}\text { Verify immunity against hepatitis B } \\
\text { and receive immunization if } \\
\text { susceptible and not previously } \\
\text { vaccinated }\end{array}$ & 15 (13.6) & $13(11.2)$ & $28(12.4)$ & 1.25 & $0.53-2.97$ & 0.580 & 1.185 & $0.504-2.786$ & 0.698 \\
\hline $\begin{array}{l}\text { Verify pertussis immunization record } \\
\text { and receive } \\
\text { immunization if last dose }>10 \text { years } \\
\text { before }\end{array}$ & $5(4.5)$ & $3(2.6)$ & $8(3.5)$ & 1.79 & $0.36-9.74$ & 0.490 & 1.244 & $0.254-6.103$ & 0.788 \\
\hline $\begin{array}{l}\text { Ask advice to doctor about } \\
\text { administration of any drug }\end{array}$ & $35(31.8)$ & $34(29.3)$ & $69(30.5)$ & 1.13 & $0.61-2.06$ & 0.682 & 1.255 & $0.657-2.397$ & 0.491 \\
\hline $\begin{array}{l}\text { Make an appointment with the } \\
\text { doctor for preconceptional } \\
\text { counseling }\end{array}$ & $32(29.1)$ & $41(35.3)$ & $73(32.3)$ & 0.75 & $0.41-1.36$ & 0.315 & 0.732 & $0.377-1.424$ & 0.359 \\
\hline Stop smoking & $36(32.7)$ & $38(32.8)$ & $74(32.7)$ & 1.00 & $0.55-1.81$ & 0.996 & 0.990 & $0.515-1.901$ & 0.976 \\
\hline Stop drinking alcohol & $29(26.4)$ & $30(25.9)$ & $59(26.1)$ & 1.03 & $0.54-1.94$ & 0.932 & 0.994 & $0.512-1.930$ & 0.985 \\
\hline Stop illicit drug use & 19 (17.3) & $10(8.6)$ & $29(12.8)$ & 2.21 & $0.92-5.41$ & 0.052 & 1.655 & $0.684-4.003$ & 0.263 \\
\hline Do physical exercise & $14(12.7)$ & $11(9.5)$ & $25(11.1)$ & 1.39 & $0.56-3.48$ & 0.437 & 1.013 & $0.399-2.573$ & 0.978 \\
\hline $\begin{array}{l}\text { Avoid contacts with toxics and } \\
\text { pesticides }\end{array}$ & $6(5.5)$ & $7(6.0)$ & $13(5.8)$ & 0.90 & $0.26-3.10$ & 0.852 & 0.689 & $0.200-2.377$ & 0.555 \\
\hline $\begin{array}{l}\text { Verify immunity against } \\
\text { toxoplasmosis and adopt preventive } \\
\text { behaviors if susceptible }\end{array}$ & $38(34.5)$ & $26(22.4)$ & $64(28.3)$ & 1.83 & $0.98-3.43$ & 0.043 & 1.808 & $0.947-3.452$ & 0.073 \\
\hline
\end{tabular}

instrument for health professionals for rapidly improving their knowledge and communicating with patients [11-22].

The recommendation on folic acid supplementation was, overall, the most frequently found on the Internet; moreover, it was significantly easier to find a correct recommendation on this subject for a health professional than for a woman of childbearing age. This result may be explained by the observation that a specific string search on this topic was provided by health professionals and not by women. However other specific search strings, as those on lifestyle and on preconceptional visit, were evenly distributed between the search groups and did not result in any difference on correct recommendation. On the other hand the high frequency of correct recommendations on folic acid supplementation may be favored by a recent campaign conducted in Italy on folic acid supplementation [29-31].

Since physicians may be influenced in their clinical decisions by information found through Google searches, they should be warned on the frequent inconsistency of data retrieved by this means. Information obtained from general search engines should always be integrated with recommendations obtained from specific medical databases. This observation seems particularly relevant, as Google is planning to release utilities 
such as Google symptoms [32], that may be used by physicians in the near future.

Information on diet if overweight or obesity were correctly reported only in $1 / 4$ of the reviewed websites. The insufficient presence of this recommendation, in particular on websites found by women of childbearing age, parallels the results from other studies that show a poor quality of nutritional information on the Internet for patients with specific medical conditions [33-35].

As for recommendations regarding vaccinations, rubella immunization is the second most frequently found item consistent with international recommendations, with no significant difference by search group (health professionals vs women of childbearing age). This result can be explained by the fact that rubella is a widely known risk factor for fetal disease. Rubella infection still presents a worrying incidence [36], and vaccination against rubella is included in an international eradication program [37]. Moreover, Italy has adopted a national plan for preconception health care promoting medical check-ups including blood tests to verify immunity against rubella [38]. Therefore, health professionals and women in childbearing age are widely informed on rubella's risks for pregnancy and on measures for its prevention.

On the contrary, the recommendation regarding pertussis immunization is one of the less represented. This finding reflects the fact that pertussis is not sufficiently recognized as a threat for newborns. In several outbreaks the maternal-newborn transmission has been observed as one of the main transmission patterns [39].

Regarding web page categories, Communities and blogs were more frequently retrieved by women, while Medical/Public Agencies were the most frequently found by health professionals. This is strongly related to the source of the search strings used for the search (respectively, women and health professional). Communities and blogs represents overall the most represented category. This is an interesting result, as it shows a general interest among Internet users for the preconception care topic. Although, it is also the website category that reports less information consistent with international guidelines. This result suggests that preconception care specialists should consider an active use of blogs, forums and other social networks as powerful media for providing women of childbearing age with correct preconception information.

Presence of commercial links in a web page was associated with a higher quality of preconception information. This result shows that industries are actually implementing promotion of health care on the web as a part of their marketing strategy. Among the websites that were reviewed, few were disclosed as property of pharmaceutical industries. We cannot exclude that other websites were driven by other companies.

\section{Strengths and limitations of the study}

The main strength of our study concerns the methodology: we investigated preconception information available on the Internet through a formal approach that helps avoiding the biases originating from arbitrary choices of keywords by study researchers. Several authors investigated quality of information found on the Internet regarding specific health topics, including cystic fibrosis [40], pediatric cancer [41], rheumatologic diseases [42], Mediterranean diet [43]. The search keywords used in these studies were chosen by the authors themselves, either simulating a search by a random user, or simulating a patient's experience [44]. Weighing suggestions from a group of users against the frequency of Google searches should increase the likelihood to perform simulations closer to real life. We recommend this methodology for the evaluation of quality of medical information on the Internet.

The main limitation of our study is that it has a cross sectional design, and it analyses a static situation at the moment when the survey has been conducted. Presence of information on the Internet, on the contrary, is intrinsically dynamic. A periodic survey of the web would constitute a precious, alternative source of information on specific public health issues.

The analysis has been conducted using only Italian search strings, therefore the results may not be generalizable to other countries. Finally, we investigated presence of specific web information using generic search strings. This may have led to an underestimation of the presence of consistent recommendations on the web. Nevertheless, we can assume that this approach reflects the average search strategy most frequently chosen by the users.

\section{Conclusion}

The present study results indicate that a strong effort is needed for implementing web communication strategies regarding preconception health, in order to guarantee a correct dissemination of recommendations consistent with guidelines.

To this aim, a successful strategy would imply investigating the most frequently used search strings, and subsequently improving the rank of websites providing correct and complete preconception recommendations through a thorough Search Engine Optimization (SEO). An additional effort should be put in the dissemination of consistent information to websites that are not directly managed by public health agencies. From this point of view, engagement in social networking and communities, being the latter the category of websites most frequently found by women, should be implemented.

With regard to health professionals, this study shows that a deep and constant update on search strategies for health information should be included in medical 
education, in order to avoid incurring in unreliable or incomplete information.

With regard to women of childbearing age, the general inconsistency of web information on preconception care confirms the crucial importance of having a physician appointment before conception in order to receive a correct preconception counseling.

In conclusion, dissemination of information on the web can be a powerful tool to guide proper preventative actions in the preconception period. Although we did explore the Italian setting only, it is likely that specific web strategies for disseminating appropriate preconception recommendations are still largely insufficient also in other settings. Studies like the one described here may help improving penetration of information and ultimately supporting healthy lifestyles aimed to prevent adverse pregnancy outcomes.

\section{Competing interests}

The authors declare that they have no competing interests.

\section{Authors' contributions}

EA coordinated the study, designed the study and participated in the writing process and in the data review. FG designed the study and drafted the manuscript. EP conducted the interviews. MVG conducted the interviews and revised the final version of the manuscript. EC performed the statistical analysis. PM conceived the study, participated in its design, AET conceived the study, participated in its design and coordination and drafted the manuscript. All authors read and approved the final manuscript.

\section{Author details}

${ }^{1}$ Bambino Gesù Children's Hospital IRCCS, Epidemiology, Unit Piazza S. Onofrio 4, 00165, Rome, Italy. ${ }^{2}$ Alessandra Lisi International Centre on Birth Defects and Prematurity, Via Carlo Mirabello 14, 00192, Rome, Italy.

Received: 25 October 2012 Accepted: 21 January 2013

Published: 25 January 2013

\section{References}

1. Seshadri S, et al: Prepregnancy care. BMJ 2012, 344:e3467.

2. American College of Obstetricians and Gynecologists: ACOG Committee Opinion number 313, September 2005. The importance of preconception care in the continuum of women's health care. Obstet Gynecol 2005, 106:665-666.

3. Wahabi HA, et al: Preconception care for diabetic women for improving maternal and fetal outcomes: a systematic review and meta-analysis. BMC Pregnancy Childbirth 2010, 10:63.

4. Berghella $\mathrm{V}$ : Best management of threatened preterm labour - how to implement the evidence into practice. BJOG 2010, 117:1313-1315.

5. Cheng TL, et al: Preconception Women's Health and Pediatrics: An Opportunity to Address Infant Mortality and Family Health. Acad Pediatr 2012, 12(5):357-359.

6. Reeve ME: Preconception health: The missing link in the $\mathrm{MNCH}$ continuum of care. Beijing Da Xue Xue Bao 2009, 41:383-388.

7. De-Regil LM, et al: Effects and safety of periconceptional folate supplementation for preventing birth defects. Cochrane Database Syst Rev 2010, (10):CD007950. doi:10.1002/14651858.CD007950.pub2.

8. Elsinga J, et al: The effect of preconception counselling on lifestyle and other behaviour before and during pregnancy. Womens Health Issues 2008, 18:S117-S125.

9. Jack BW, et al: The clinical content of preconception care: an overview and preparation of this supplement. Am J Obstet Gynecol 2008, 199:S266-S279.

10. Health Council of the Netherlands: Preconception care: a good beginning. The Hague: Health Council of the Netherlands; 2007.
11. Bunting $L$, Boivin J: Decision-making about seeking medical advice in an internet sample of women trying to get pregnant. Hum Reprod 2007, 22:1662-1668

12. Sankar NS: Health information on the Web: pregnancy. J R Soc Promot Health 2000, 120:94-95.

13. Lagan BM, et al: A Web-based survey of midwives' perceptions of women using the Internet in pregnancy: a global phenomenon. Midwifery 2011, 27:273-281.

14. Larsson M: A descriptive study of the use of the Internet by women seeking pregnancy-related information. Midwifery 2009, 25:14-20.

15. Krause $R$, et al: Can emergency medicine residents reliably use the internet to answer clinical questions? West J Emerg Med 2011, 12:442-447.

16. Tang $\mathrm{H}, \mathrm{Ng} \mathrm{JH}$ : Googling for a diagnosis-use of Google as a diagnostic aid: internet based study. BMJ 2006, 333:1143-1145.

17. Johnson PT, et al: A comparison of world wide web resources for identifying medical information. Acad Radiol 2008, 15:1165-1172.

18. Waksman R: Google medicine. Cardiovasc Revasc Med 2012, 13:1-2.

19. Kahane $S$, et al: Must we appear to be all-knowing?: patients' and family physicians' perspectives on information seeking during consultations. Can Fam Physician 2011, 57:e228-e236.

20. Romano M, et al: Use of the internet by Italian pediatricians: habits, impact on clinical practice and expectations. BMC Med Inform Decis Mak 2012, 12:23.

21. Wolters Kluwer Health. Wolters Kluwer Health 2011 Point-of-Care Survey: Wolters Kluwer Health. Wolters Kluwer Health 2011 Point-of-Care Survey; 2012 http://www.wolterskluwerhealth.com/News/Documents/White\%20Papers/ Wolters\%20Kluwer\%20Health\%20Survey\%20Executive\%20Summary-Media. pdf2012.

22. Google/Hall \& Partners: Connecting with Physicians Online; 2012. http://www. thinkwithgoogle.com/insights/library/studies/connecting-with-physiciansonline-searching-for-answers/.

23. Shedlosky-Shoemaker $R$, et al: Tools for assessing readability and quality of health-related Web sites. J Genet Counsel 2009, 18:49-59.

24. U.S. Department of commerce United States Census Bureau. Computer and Internet use; http://www.census.gov/hhes/computer/.

25. Seybert H: Industry, trade and services. Eurostat Statistics in focus. 66/2011; ISSN 1977-0316.

26. ISTAT: Istituto nazionale di Statistica ISTAT: Cittadini e nuove tecnologie. Anno 2010, 2012. http://www.istat.it/it/archivio/48388.

27. Alexander D, Marten H, Tobias H, Werner BK, Ingo M: "Benchmarking ICT use among General Practitioners in Europe Final Report"; 2008. http://ec.europa. eu/information_society/eeurope/i2010/docs/benchmarking/ gp_survey_final_report.pdf

28. Google Adword Keyword Tool; https://adwords.google.com/o/Targeting/ Explorer?_c $=1000000000 \& \_u=1000000000 \&$ ideaRequestType $=$ KEYWORD_ IDEAS.

29. De Santis M, et al: Folic Acid Use in Planned Pregnancy: An Italian Survey. Matern Child Health J 2012, Epub ahead of print.

30. Ronfani $L$, et al: Periconceptional supplementation with folic acid for the primary prevention of congenital malformations. Pediatr Med Chir 2004, 26(2):105-111

31. Taruscio D, et al: Folic acid and primary prevention of birth defects. Biofactors 2011, 37:280-4

32. Zeiger R: Improving health searches, because your health matters; 2012.

33. Joshi MP, et al: Quality of nutrition related information on the internet for osteoporosis patients: a critical review. Technol Health Care 2011, 19:391-400

34. Traver MA, et al: Is the Internet a reliable source for dietary recommendations for stone formers? J Endourol 2009, 23:715-7.

35. Guardiola-Wanden-Berghe $R$, et al: Evaluating the quality of websites relating to diet and eating disorders. Health Info Libr J 2011, 28:294-301.

36. Best JM, et al: Reducing the global burden of congenital rubella syndrome: report of the world health organization steering committee on research related to measles and rubella vaccines and vaccination, June 2004. J Infect Dis 2005, 192:1890-7.

37. World Health Organization Europe: Eliminating measles and rubella and preventing congenital rubella infection: WHO European Region strategic plan 2005-2010; 2005. ISBN 9289013826.

38. D.M. 10 SETTEMBRE 1998. Aggiornamento del d.m. 6 marzo 1995 concernente l'aggiornamento del d.m. 14 aprile 1984 recante protocolli di accesso agli esami di laboratorio e di diagnostica strumentale per le donne in stato di 
gravidanza ed a tutela della maternità; http://www.trovanorme.salute.gov.it/ dettaglioAtto?id=19991.

39. Peters TR, et al: Potential impact of parental Tdap immunization on infant pertussis hospitalizations. Vaccine 2012, 30(37):5527-5532.

40. Pandolfini C, et al: Quality of cystic fibrosis information on Italian websites. Inform Health Soc Care 2009, 34:10-7.

41. Stinson JN, et al: Perspectives on quality and content of information on the internet for adolescents with cancer. Pediatr Blood Cancer 2011, 57:97-104.

42. Stinson JN, et al: Surfing for juvenile idiopathic arthritis: perspectives on quality and content of information on the Internet. J Rheumatol 2009, 36:1755-62.

43. Hirasawa R, et al: Quality of Internet information related to the Mediterranean diet. Public Health Nutr 2012, 15:885-93.

44. Scullard P, et al: Googling children's health: reliability of medical advice on the internet. Arch Dis Child 2010, 95:580-2.

doi:10.1186/1472-6947-13-14

Cite this article as: Agricola et al: Does googling for preconception care result in information consistent with international guidelines: a comparison of information found by Italian women of childbearing age and health professionals. BMC Medical Informatics and Decision Making 2013 13:14.

\section{Submit your next manuscript to BioMed Central and take full advantage of:}

- Convenient online submission

- Thorough peer review

- No space constraints or color figure charges

- Immediate publication on acceptance

- Inclusion in PubMed, CAS, Scopus and Google Scholar

- Research which is freely available for redistribution 